\title{
Alphonsus de Guimaraens e os jornais: fragmentos de uma bibliografia lacunar
}

\author{
Francine Fernandes Weiss Ricieri \\ Universidade Estadual de Campinas
}

\section{1) Um mineiro na Paulicéia}

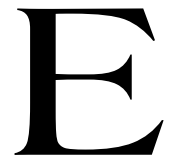

m 1890, o jovem poeta mineiro Afonso Henriques da Costa Guimarães (então com vinte anos) parte para São Paulo em companhia do amigo (e também poeta) José Severiano de Resende. Ambos almejam o ingresso na Faculdade de Direito e, principalmente, ao que tudo indica, reconhecimento literário. Naquela década, vários periódicos acolhiam as produções dos "novos", como se designavam os simpatizantes das tendências simbolistas e decadentistas: Novidades, Revista ilustrada, O paulistano e O mercantil. O último, em especial, mantinha semanalmente uma página literária em que figuraram as primeiras produções de Cruz e Sousa e vários outros.

Nos anos seguintes, os amigos mineiros, em companhia do colega de curso Adolfo Araújo, chegam a dedicar-se quase profissionalmente ao jornalismo paulistano, circulando seus escritos também no Comércio de S. Paulo, no Correio paulistano no Diário mercantil e n' O Estado de S. Paulo. Em texto de 1921, Cézar Câmara de Lima Campos refere-se às incursões pelos jornais e revistas de então:

E como os Decadentes de Paris, já imitados pelos nossos irmãos, os Nefelibatas de Lisboa, que tinham, então, à frente Eugênio de Castro, o cintilante de Oaristos e Belkiss, criamos, também, aqui, nós os simbolistas do Rio, o nosso François I, que foi, então, o célebre e celebrado Café Pelotense, já, antes da nossa existência, freqüentado pelos "Insubmissos", o grupo de pintores a que pertencera também Gonzaga Duque, quando preocupado exclusivamente de pintura e crítica de arte. Aclamávamo- 
nos, com convicção de que se alheava a modéstia: "Magnificentes da Palavra Escrita" e nos subintitulávamos: "Romeiros da Estrada de SanTiago".

Éramos ao todo, uns vinte, vinte exóticos, vinte malucos, vinte belezas. E daí foi que partimos, unidos, para a escalada das evidências de que necessitávamos e se faziam necessárias: os jornais, as revistas, os editores, os palcos, que conquistamos, por fim, começando, três ou quatro anos depois, a dispersão ... ${ }^{1}$

Se, por um lado, necessitava-se de um "clima" algo fumarento de "Café" intelectual que permitisse aos "Magnificentes da Palavra Escrita" sentir-se como tal, havia também a necessidade da formação de um grupo (de incentivo e confirmação mútuos) e da busca de meios materiais capazes de lhes conferir a presença concreta em um mundo sobre o qual aparentemente desejavam apenas sobrevoar.

Unidos, lançavam-se a jornais e guetos também os "romeiros" de São Paulo. Lá, além do restaurante "Vecchio Leone di Caprera" (mencionado na crônica de Alphonsus "Cai a garoa" $)$, Freitas Vale, o Jacques d'Avray, transformou sua luxuosa residência em Vila Mariana na "Vila Kirial" (de nome especialmente sugestivo), onde se encontravam regularmente, além dos amigos citados, Alberto Ramos, Augusto Viana do Castelo e outros artistas e poetas.

O recurso a pseudônimos latinizados ou afrancesados evidentemente era parte do processo de coesão dos grupos. O jovem Afonso Henriques (que confessaria mais tarde a um dos filhos haver preferido São Paulo a Lisboa para seu Direito em virtude de um sentimento nacionalista importante no momento) empenha-se então em trocar a homenagem ao rei luso por um nome mais conveniente. Uma olhadela nas contribuições dos órgãos de então evidencia que o empenho foi incansável: Affonso Guimarães; Affonso de Guimarães; Alfonso Guy; Guy d'Alvim; Affonso Guimaraens; Alfonso Guimaraens; Alphonsus de Guymar; Dom Alphonsus; Alphonsus o Mystico +; Senhor Alphonsus, o Mystico; Vicomte Antoine de Grandeuil; Alphonsus de Vimaraens; Alphonsus de Guimaraens.

O que pode parecer uma simples e algo ridícula consagração de uma seita de esquisitos era também e principalmente o estabelecimento

\footnotetext{
${ }^{1}$ CAMPOS, 1921. In: MURICY, 1951-1952, p. 560-561.

${ }^{2}$ GUIMARAENS, 1960, p. 459-462.
} 
e a confirmação renovada de um estatuto artístico que se importava e se implantava por estas plagas. A atividade na imprensa, ainda que menos curiosa, era tão decisiva quanto o ar dândi, a indumentária apurada e o requinte que o citado Cézar Câmara L. Campos sublinhava, ainda em seu texto de 1921, em Alphonsus de Guimaraens: "um de nossos mais queridos romeiros, figura de alto requinte à Brummel ..., na toilette e no trato ..., esse delicadíssimo e triste Alphonsus que ainda há pouco a morte levou" (...). ${ }^{3}$

As contribuições do jovem Alphonsus em O mercantil iniciaramse oficialmente em 3 de janeiro de 1891, conforme aponta Brito Broca:

Manuseando as coleções de "O mercantil", de 1891, encontrei a 3 de janeiro a seguinte notícia: "Passará a trabalhar nesta folha o nosso inteligente colaborador Afonso Guimarães. Poeta delicado e cronista de aptidão, esperamos que o digno moço preste ao "Mercantil" sua dedicação." Em números anteriores já figuram alguns trabalhos em prosa e verso do "digno moço", então primeiro anista de Direito. Iria ele agora aparecer regularmente na folha, como redator. Duas sessões do mesmo gênero manterá ele por algum tempo no "Mercantil": "Trechos de Crônica" e "Spleen" ambos tipo (sic) da croniqueta jornalístico-literária em fragmentos. Enquanto isso, comparece assiduamente com poesias na seção "O Parnaso". ${ }^{4}$

Em um dos pouquíssimos textos da bibliografia sobre o escritor dedicados ao tema, Broca, a propósito das crônicas publicadas no jornal, afirma já serem superiores, lá, as produções do poeta. Ressalta, contudo, que as deficiências do cronista são também as apresentadas pelo gênero na época:

O simbolismo na poesia deu no Brasil alguns belos frutos, em que pese a opinião de José Veríssimo; na prosa produziu geralmente efeitos desastrosos. (...) O gênero de crônica praticado por Alphonsus de Guimaraens no "Mercantil" era de evidente inspiração simbolista, gênero que prevaleceu durante muito tempo entre nós e cuja influência foi superada, primeiramente por um Machado e um Bilac; depois pelos que continuaram a tradição destes na primeira década do século: um João do Rio e um Gilberto Amado. ${ }^{5}$

${ }^{3}$ CAMPOS, 1921. In: MURICY, 1951-1952, p. 561.

${ }^{4}$ BROCA, 1951, p. 4.

${ }^{5}$ BROCA, 1951, p. 4. 
Para Broca, em Alphonsus, a influência simbolista teria sabor romântico byroniano já que, como prosador, "pagava um tributo às cloroses da época". Ironiza o crítico: "São bem significativos os elogios entusiásticos e panegirísticos, com que ele saudava o aparecimento do livro Baladilhas de Coelho Neto (27-02-1891), crônicas e fantasias mais ou menos do gênero das que escrevia em 'Spleen'”.

As crônicas eram alternadas com "notações críticas, comentários humorísticos sobre fatos do dia" e mudanças bruscas de tom nas páginas. Broca menciona exemplos dessas alternâncias de tom, lembrando, contudo, terem as crônicas o clima geral de tristeza romântica, "com laivos de satanismo, visões tumulares e sombras, parecendo denunciar leituras mal assimiladas de Poe". ${ }^{6}$

Em março de 1895, já formado, com dificuldades financeiras, Alphonsus vê-se impossibilitado de permanecer em São Paulo e assume o posto de Promotor de Justiça na cidade de Conceição do Serro, interior de Minas. Não cessa, contudo, as atividades jornalísticas, colaborando assiduamente com A gazeta, fundada pelo amigo Adolfo Araújo. Cartas e textos da época atestam a influência pessimista que o isolamento intelectual terá sobre o temperamento sensível e já um tanto mórbido do escritor.

A possibilidade de mudança surge de um modo algo ingrato, em 1903, quando, estando o poeta já casado e com filhos, ocorre a supressão do cargo de juiz substituto, por ele ocupado. Na ocasião, Adolfo Araújo propõe-lhe emprego n'A gazeta, com oferta salarial de 400 mil réis. Alphonsus recusa o convite, embora mantenham-se suas colaborações no jornal paulista. João Alphonsus, o filho biógrafo, atribui a decisão a "sua índole pouco propensa às aventuras materiais e em que o amor à fixação aumentava com a idade - apesar de ter somente 33 anos". ${ }^{7}$ O fato é que, por aqueles meses, Joaquim Soares Maciel Júnior, presidente da Câmara local, funda o Conceição do Serro, modesto órgão de divulgação, e o entrega à direção do poeta municipal Alphonsus de Guimaraens.

\footnotetext{
${ }^{6}$ BROCA, 1951, p. 4.

7 GUIMARAENS, João Alphonsus de, 1960, p. 41.
} 


\section{2) Operosa oficina}

Alphonsus teria composto o Conceição do Serro de 20 de março de 1904 até 18 de dezembro do mesmo ano. Depois dessa data, reassumido o cargo de juiz da comarca, teria colaborado com o veículo, que vai existir até 12 de fevereiro de 1905, totalizando 45 edições. Segundo Alphonsus Filho, os cinco últimos números, embora não trouxessem seu nome no cabeçalho, também teriam sido feitos por ele. Possibilidade muito razoável, já que o poeta era "o factotum do jornal", como de praxe em periódicos do interior, nos quais o redator, às vezes desempenhava "misteres até de impressor ..."

Inovação no município, "o primeiro número foi lançado à publicidade às duas horas da tarde do dia 20 de março de 1904, sendo festivamente recebido com salvas de dinamite e pela banda de música local"9 aos acordes da "Euterpe Augusta". Nele estão presentes as necessárias afirmações de princípios e intenções, conforme esclarece Mário Casassanta em "O jornal de Alphonsus":

Em primeiro lugar, vem o artigo de apresentação. Assina-o o coronel Soares Maciel. É natural. Chefe da administração e da política explica o objetivo do jornal, declara que se acha confiado ao festejado autor do Septenário das Dores, de Dona Mística e do Kiriale, "a quem, por felicidade, em boa hora entregamos tão difícil encargo". (...) O segundo artigo, que vem sem assinatura, é evidentemente de Alphonsus. Maciel diz na apresentação, com louvável compreensão num chefe político de um município, de mais a mais em 1904, que a ele, Alphonsus, pertence o programa da folha; "a nós, porém, dentro da órbita limitada dos nossos acanhados conhecimentos, cabe o dever de auxiliá-lo..."10

Analisando a edição, Casassanta não obscurece as relações do escritor com a política local (afinal, um político os financiava - a ele e a "seu" jornal), aliás, declaradas no próprio número de abertura e nas posições assumidas em edições subseqüentes:

\footnotetext{
${ }^{8}$ COELHO, 1934, p. 33.

${ }^{9}$ COElHO, 1934, p. 26.

${ }^{10}$ CASASSANTA, 1946, p. 3.
} 
O jornal interessar-se-á pela política, como ciência de bem governar o estado e o Município, mas não pretende meter-se em discussões de cunho pessoal. Aplaudirá, assim, o governo do Estado, enquanto se mantiver com lisura. Tudo isso, porém, se expressará com boa língua, em termos comedidos para que o jornal constitua um sacerdócio e não uma estátua do gladiador Pasquino. / A linguagem, diz ele, será sempre lídima e correta, como convém a quem escreve para um povo civilizado. ${ }^{11}$

Esta concepção da linguagem enquanto elemento se não civilizatório ao menos denotador de civilidade percorre vários momentos do cronista. O número inaugural do Conceição do Serro estende tal concepção à literatura: formadora e fonte, a ela cabe dar um tom mais alto ao jornal. A atividade da imprensa, por si só progressista e benfazeja, pode transcender, assim, as limitações inegáveis do veículo em questão sem negligenciar as ocupações imediatas a que ele se destina:

Surge, pela primeira vez, nesta cidade um periódico; bem-vindo será por certo para todos aqueles que compreendem a missão progressista e benfazeja do jornalismo. / Órgão oficial do município, tratará paralelamente das necessidades e interesses deste e do Estado, bem como da comunhão brasileira, na sua humilde esfera será a almenara que velará com seu clarão protetor pelo sossego, paz e prosperidade dos nossos conterrâneos. Vem, de viseira erguida, combater pelo bem de todos; velar pela justiça é o seu emblema, é a insígnia da bandeira que desfralda. / A par do direito, agricultura, comércio, viação e indústrias (da extrativa, principalmente, dadas as condições do nosso solo e subsolo), tratará também das letras propriamente; pois que a literatura é e sempre será a fonte primitiva dos conhecimentos humanos. / Assim, sempre que o espaço tão acanhado o permitir, serão estampados trechos de prosa e versos de escritores laureados, quer portugueses quer brasileiros; a mocidade aprenderá a amar as belasartes, este consolo de todos entre os amargores da vida. ${ }^{12}$

De viseira erguida, combatendo o bom combate, o jornalzinho, nesse mesmo número, publica (a par do direito, da agricultura e companhia) uma "Canção" de Severiano de Resende acrescida de comentário do autor associando-a às canções de S. Juan de Ia Cruz e de juízos críticos elogiosos

\footnotetext{
${ }^{11}$ CASASSANTA, 1946 , p. 3.

12 GUIMARAENS FILHO, 1995, p. 149-150.
} 
do editor com alusões à "poesia moderna" e à obra de Baudelaire e Verlaine. O jornal traz, ainda, uma crônica de Alphonsus sobre o voto da mulher, "que combate com graça". ${ }^{13}$

Considerando-se a dificuldade de acesso às publicações,${ }^{14}$ vale transcrever os minuciosos comentários de Mário Casassanta sobre o conteúdo do restante do jornal:

Ao lado dessa parte de letras, que olhamos com admiração e inveja, ainda hoje, depois de tantas águas que correram, refere-nos o primeiro número um punhado de coisas interessantes. No artigo-programa, por exemplo, alude-se à ação do governo, "mau grado a terrível crise econômica que atravessamos". Vede, antigos. Já em 1904 tínhamos essa novidade, o que é sinal de que crise não mata ninguém. No noticiário há uma nota acerca de Bernardo Guimarães, cuja morte o mês de março lembrava. Traz uma informação de que o arraial de Conceição tinha em 1831 apenas 150 casas; em 1841 foi elevado a vila e em 1851 a cidade. Anuncia-se a visita do dr. Joaquim Sena, um Costa Sena, cientista e político, filho da terra. Consigna a manifestação ao José de Almeida, a partida do deputado Pedro Luiz para Ouro Preto, informações do fôro. Não vos lembraremos o sortimento do mercado, porque não queremos dilacerar-vos a alma, assinalando apenas e para amostra que uma dúzia de frangos se vendia a seis cruzeiros, um (sic) dúzia de queijos a seis cruzeiros, oitenta litros de arroz limpo a quatorze cruzeiros, uma dúzia de ovos a trezentos e vinte centavos...

Não menos sugestiva é a seção de anúncios. Advogados, médicos, farmacêuticos, comerciantes, alfaiates, fotógrafos. O proprietário de um bilhar anuncia whisky, old-tom, kirch, birr. Três

${ }^{13}$ CASASSANTA, 1946, p. 3.

${ }^{14} \mathrm{O}$ jornal não consta do acervo da Biblioteca Nacional (Rio de Janeiro), da Casa de Rui Barbosa (mesma cidade), da Biblioteca Pública Municipal de Belo Horizonte, do Arquivo Público Mineiro, das bibliotecas da Universidade Federal em Belo Horizonte, do Museu Casa Alphonsus de Guimaraens (em Mariana), da Biblioteca Mário de Andrade (São Paulo), do acervo das bibliotecas da Universidade de São Paulo e de outras bibliotecas pesquisadas no interior do estado de São Paulo e no estado do Paraná. Alphonsus de Guimaraens Filho declara, na obra citada, haver recebido de Joaquim Ribeiro Costa uma coleção incompleta do periódico, além de ter visto muitos recortes e números avulsos em Conceição do Mato Dentro (antiga Conceição do Serro). Ele não se lembra de ter visto uma coleção completa. 
senhores anunciam rancho para os tropeiros. Um negociante, de mudança para outro lugar, anuncia as suas mercadorias, esperando "que os seus devedores venham saldar os seus respectivos débitos". O Miranda do bilhar comunica que "para perturbar a monotonia dos sapos, enfeitou o seu salão com as mais gentis gaiolas, onde trinam canários belgas". Desfilam os ourives, o dentista, o tabelião. Uma colméia a pequena cidade! Para não desmentir o programa, que tanto relevo confere às letras, até nos anúncios se revela o espírito do jornal: anuncia-se, a par do Tratado completo de aritmética, de Arthur Guimarães, a venda do Septenário das Dores de Nossa Senhora, Dona Mística e Kiriale, picos altos de nossa sensibilidade. ${ }^{15}$

Como se vê, devotando-se às atividades que o justificam enquanto órgão do município, o jornal acaba por "contagiar" também as letras que animam seu "espírito", em um "contágio" que é visivelmente rua de mão dupla. O mesmo Alphonsus que negocia em cartas trocadas com os amigos $^{16}$ detalhes específicos de publicações de suas obras, ou discute custos, ou pede que se investiguem abatimentos, anuncia a venda de seus livros ao lado de um Tratado de aritmética.

Faz parte do jogo a duplicidade apenas aparentemente contraditória. O jovem dândi que, entre seus pares, desfrutava o espaço apartado da Vila Kirial era o mesmo jornalista que, escrevendo, ganhava, a um tempo, seu tanto de notoriedade e o indispensável numerário que o conservava na

${ }^{15}$ CASASSANTA, 1946, p. 3.

${ }^{16}$ Alphonsus de Guimaraens Filho (GUIMARAENS FILHO, 1995, p. 145- 146) transcreve carta de Álvaro Viana a Alphonsus:

"Mestre Alphonsus.1 Belo Horizonte, 21 de Outubro de 1902.1 Abraço-te. Segue, enfim, o Kiriale, chegado ontem. Vão 14 exemplares, salvo engano. Os que precisares vão quando quiseres, não fazendo eu maior remessa agora por falta de numerário. Recebi a tua carta. Como é preciso pagar ao Figueirinhas até o dia 25 deste, vou mostrar a tua carta ao Artur para que ele me dê os $100^{\circ}$ de que falas na tua carta (...). Vou fazer remessa do Kiriale aos jornais do Rio. Sim? Ou queres tu mesmo fazê-Io? Por estes dias mando-te mais uns 50 exemplares. Vou remeter ao nosso Caro d' Avray uns exemplares, para que ele os exponha à venda em São Paulo. Estou apenas à espera dos originais do Horácio para publicar o Horus, que está magnífico. Vai este papel mesmo porque não tenho outro, e nem com que comprar; o mês já vai no fim e é condição essencial da quebradeira. Abraça-te afetuosamente o/ Teu/ Álvaro." 
Paulicéia. Ou ainda, o poeta maduro "do amor e da morte", reticente e caladão não era senão o juiz de direito pendurado de filhos que recorria aos "pintos magros" da colaboração (muitas vezes satírica) na imprensa para paliativas suturas no esfarrapado orçamento doméstico.

Além disso, se o Conceição do Serro serviu para pagar o salário do homem de leis desempregado, serviu também para exteriorizar alguns aspectos de sua concepção de literatura e sua admiração por alguns homens do ramo. Alphonsus de Guimaraens Filho dedica vários capítulos da referida obra à análise das páginas do Conceição do Serro. Em alguns, analisa as publicações de escritores feitas por Alphonsus no jornal que dirigiu. Guimaraens Filho entende que um exame desta colaboração levaria, se não a todas as preferências do poeta (já que algumas publicações obedeceriam a influências de amizade), pelo menos a algumas delas. A propósito, destaca a afeição demonstrada por escritores portugueses como Camões, Diogo Bernardes e Antero de Quental.

Bem visível seria também a predileção por Cruz e Sousa, que teve alguns poemas publicados no jornal a que não faltavam inclusive versos de Bilac. O que teria insultado muitos de seus antigos colegas de São Paulo seria, na visão do filho, a manifestação da preocupação de não ser sectário e, mesmo, uma possível homenagem à escola a que Alphonsus se opusera. Havia também poemas do próprio diretor do jornal, inéditos ou retirados dos três livros que já editara, além de colaborações (de cunho normalmente político) de Soares Maciel. Freqüentes colaboradores eram Archangelus de Guimaraens e Severiano de Resende, ao lado de eventuais contribuições de outros amigos de juventude e moradores da região.

Da operosa oficina do Conceição, é possível que se articulasse (ao lado dos anúncios - alguns deles versificados -, dos embates de poder, das charadas para distração local e das variáveis ligadas à produção econômica do município) uma poética pessoal organizada no sentido de obter talvez que a mocidade viesse a "amar as belas-artes", este "consolo de todos os amargores da vida". E, bem articulada com os sinais de seu tempo, a eventual poética do jornalzinho (contemporâneo dos primeiros passos da Academia Brasileira de Letras) abria licitamente seu espaço entre os "laureados" - aos promissores, aos entusiasmados, aos injustiçados, aos membros do grupo, aos amigos de infância ... ao político que pagava a conta da festa.

Ora, é evidente que as ligações com a política estavam a quilômetros de qualquer possível (?) neutralidade. Tratava-se de um órgão 
oficial, o que se estampava inclusive nas divertidas sátiras da lavra do poeta responsável. Durante a campanha, o candidato da situação era um certo coronel Joaquim Soares Maciel Júnior, enquanto na oposição figurava o médico Casimiro de Sousa. Em epigramas assinados "Catimbau" e numa série de "Palestras", sob pseudônimos vários, tratava-se da campanha e satirizavam-se os médicos. Vitorioso o oposicionista, passarase a ter o regime de duas câmaras municipais, motivo de novas crônicas, novas sátiras, novos epigramas. Não por acaso, quando, em 1906, o poeta pleiteia o lugar de juiz municipal da comarca, opõe-se "o médico das sátiras, agora chefe político". ${ }^{17}$

Impossibilitado de seguir a carreira jurídica em Conceição do Serro, Alphonsus de Guimaraens transfere-se para Mariana, em 1906. Um ano depois da mudança, já se encontram contribuições suas no jornal local, Ogerminal. Naquela cidade, ele se dedica aos encargos de juiz municipal e à colaboração na imprensa: A gazeta, de São Paulo, o Jornal do comércio, de Juiz de Fora, revistas cariocas como Fon-Fon! e O curvelano do amigo Álvaro Viana.

Dessa época (1909), seriam os poemas publicados em Fon-Fon! com o pseudônimo de João Ventania, de "Riacho de Vento". Em texto de 1958, Antônio Crispim (pseudônimo de Carlos Drummond de Andrade) ${ }^{18}$ relata que, percorrendo coleção de velhos jornais na Biblioteca Nacional, deparou com os versos satíricos de um certo João Ventania, de Riacho do Vento. Certo de tratar-se de pseudônimo, identificou Alphonsus como o verdadeiro autor com a ajuda de artigo de Aurélio Buarque de Holanda. ${ }^{19}$

A colaboração teria se estendido de 27 de março a 7 de agosto de 1909 (ressalvado, segundo Crispim, o que pudesse haver no segundo semestre de 1908). São arroladas as datas de coleções do Fon-Fon! pesquisadas e relacionam-se os títulos dos poemas encontrados, transcrevendo-se alguns ${ }^{20}$ e anotando-se, ainda, os números da coleção que estavam "fora do lugar" na Biblioteca. Em comentário final, afirma:

${ }^{17}$ GUIMARAENS FILHO, 1995, p. 99-100.

${ }^{18}$ CRISPIM (Carlos Drummond de Andrade), 1958, p. 23-24.

${ }^{19}$ HOLANDA, 1949, p. 6.

${ }^{20} \mathrm{Nem}$ todos os poemas divulgados por Drummond foram transpostos para a Obra completa (GUIMARAENS, 1960). Alphonsus de Guimaraens Filho, a propósito, declarou ter aproveitado "o que se nos afigurou ser essencial de João Ventania". 
Os versos de João Ventania satirizam fatos políticos, metem à bulha os gramaticistas (que publicam então na imprensa) ou contam anedotas. No comentário político, não há índices de partidarismo. O poeta se diverte, apenas, com a fauna parlamentar, os bajuladores, os fraudulentos e o vaidosos. Distrai-se, ainda, zombando dos médicos, vítimas clássicas do epigrama. Não há vitríolo nas sátiras, mas apenas a malícia de quem sabe farejar o ridículo oculto na gravidade. E que não tem muitas ilusões sobre o homem. ${ }^{21}$

O último capítulo das incursões de Alphonsus de Guimaraens pelos jornais da época escreve-se a partir de 1915, quando surge, em Mariana, o periódico $O$ alfinete, um jornal humorístico em que colabora abundantemente com versos satíricos e sérios, oculto em pseudônimos. Freqüentemente, o que publicava em $O$ alfinete ia assinado com o nome do marianense alfinetado: Joaquim Araújo, José Candinho, Dandico, Bento de Oliveira, Jovelino Gomes, Raimundo Manecas. Os moradores da cidade, em depoimentos posteriores, lembravam-se sempre da estratégia com bom humor, o que faz pensar em uma certa sintonia entre o poeta exilado (ou satirista em exercício) e seu público de sapateiros, coveiros, delegados ... Difícil saber o que pensavam dos versos de inspiração simbolista, mas recortes das brincadeiras d' O alfinete eram guardados com cuidado pelo menos até 1949, segundo depoimento de Aurélio Buarque de Holanda. Fechando a questão, um morador de Mariana lhe dissera a respeito do poeta: "Um pândego!"22

\section{3) Seleções, exclusões, (pre)juízos}

Os versos humorísticos de Alphonsus - tanto do Conceição do Serro quanto d'O alfinete ou de Fon!Fon! foram recolhidos por Alphonsus de Guimaraens Filho para a edição da Obra completa, de 1960. O filho optou por não fazer um levantamento completo dos trabalhos do gênero, separando apenas algumas poesias de Mariana (O alfinete e O germinal) e de Conceição do Serro. Também não conseguiu obter toda a coleção de O alfinete. Na Obra completa transcrevem-se, ainda, alguns dos

${ }^{21}$ CRISPIM (Carlos Drummond de Andrade), 1958, p. 24.

${ }^{22}$ CRISPIM (Carlos Drummond de Andrade), 1958, p. 6. 
anúncios que Alphonsus fazia para seu jomal²3 e alguns "epitáfios"24 jocosos destinados aos marianenses com que convivia.

No ano de 1920, o próprio Alphonsus de Guimaraens selecionara algumas de suas crônicas dispersas pela imprensa e publicara a obra Mendigos, pela Tipografia da Casa Mendes, de Ouro Preto:

Com o título de Mendigos, "páginas de Alphonsus de Guimarães /sic/ , da Academia Mineira, da Academia Piauiense", reuniu o A. em liv. uma seleção de crônicas que veio espalhando pelos jornais desde a mocidade. Encontramos várias dessas crônicas nas coleções de jornais que consultamos, especialmente em Conceição do Serro, O germinal (Mariana) e A gazeta (SP). Na contracapa de Mendigos vem anunciado ainda outro livro de crônicas do autor A.: seriam as Crônicas de Guy d'Alvim, um dos pseudônimos que ele usou com mais freqüência, volume que infelizmente não chegou a organizar. ${ }^{25}$

Praticamente todos os textos de Mendigos são acrescidos de observações, em nota : "grandemente modificada pelo autor para sua inserção em livro"; "muito modificada"; "o autor introduziu grandes modificações"; "refundida para inserção em livro". ${ }^{26}$ Tais cuidados permitiriam, caso viessem a ser estudados, que se buscassem maiores esclarecimentos a propósito da convivência do jornalista com o escritor. Sua (algo óbvia) consciência da especificidade dos meios materiais de divulgação de seus escritos, por outro lado, pode ser observada pelo cotejo entre a leveza assumida que emprestou ao material ligeiro da imprensa e a minúcia estudada com que programou e perseguiu as publicações de seus livros de poemas.

Já em janeiro de 1894 o escritor declarava em carta ao amigo Jacques d'Avray estar preparando a obra Dona Mística para publicá-la pela Imprensa Oficial, em Minas Gerais - o que não chega a se concretizar. Em abril do mesmo ano, anuncia ter escrito o poema Câmara ardente e, em

${ }^{23}$ GUIMARAENS, 1960, p. 730.

${ }^{24}$ GUIMARAENS, 1960, p. 569-571.

${ }^{25}$ GUIMARAENS, 1960, p. 719. (As notas foram preparadas pelos filhos João Alphonsus e Alphonsus de Guimaraens Filho para as edições das Poesias de 1938 e 1955. Rafae1 Millán retrabalhou, resumiu e reorganizou-as para adequação aos critérios da editora Aguilar.)

${ }^{26}$ GUIMARAENS, 1960, p. 719-720. 
janeiro de 1896, envia a Jacques seu manuscrito pedindo-lhe que faça editar 500 exemplares. Solicita uma tipografia germânica, recomenda que o papel seja de qualidade, sugere caracteres antigos. Chega a enviar 300 cruzeiros para realizar a operação. Em dezembro, após um longo silêncio, escreve anunciando seu noivado e suspendendo a publicação. Na mesma carta informa estar compondo o "Poema Setenário das dores" e fornece detalhes. As três obras acabam saindo só em 1899, sob a supervisão do amigo Mário de Alencar. Setenário das dores de Nossa Senhora e Câmara ardente, em volume único, com tiragem de 500 exemplares pela Tipografia Leuzinger, no Rio de Janeiro e, apenas alguns meses depois, Dona Mística, com tiragem de 250 exemplares.

Em 1900, Alphonsus pensa na publicação de Kiriale e solicita a Jacques D' Avray pesquisar o custo da modesta tiragem de 100 exemplares. Revela intenção de que o amigo providenciasse a capa segundo seu gosto, desde que fosse bem litúrgica, com "o perfume de um livro de horas". Estava resolvido a tirar o menor número de volumes possível, somente para oferecer. A obra acaba por ser editada no Porto, apenas em 1902, na Tipografia Universal.

Este Alphonsus persistente e empenhado (ainda que cada vez mais pobre) esmorece quando se trata do fruto dos jornais. ${ }^{27}$ Visivelmente dedica muito menor atenção à produção em prosa que, não obstante, com freqüência pensa em organizar. No último número do Conceição do Serro (1906), havia já uma nota anunciando o lançamento, "em breve", das Crônicas de João Carrilho, com preço "ao alcance de todas as bolsas". O jornal fecha e não chega a ser realizada a publicação. É possível que posteriormente João Carrilho (pseudônimo então mais freqüentemente adotado pelo escritor) tivesse sido substituído pelo Guy d’Alvim, cujas crônicas vêm anunciadas na contracapa de Mendigos. De qualquer forma, o projeto permaneceu irrealizado:

Para a organização das Crônicas de Guy d' Alvim, não dispusemos de uma orientação segura ou de qualquer critério fixado pelo A. a respeito do aproveitamento do grande número de crônicas que deixou espalhadas pela imprensa, especialmente no seu jornal Conceição do Serro, no órgão marianense O germinal e em A gazeta, de São Paulo.

\footnotetext{
${ }^{27}$ É bem verdade que muitos de seus poemas saíram em jornais e só foram para a edição em livro postumamente.
} 
Tais crônicas nem sempre aparecem assinadas por Guy d' Alvim, já que era grande o número de pseudônimos usados (...). Reunir todas as crônicas de Alphonsus, esparsas pelo jornais citados, é tarefa que demanda tempo. Resolvemos, por isso, realizá-la em parte, dando apenas uma seleção das crônicas insertas em Conceição do Serro e as que apareceram em O germinal de 1906 a 1911, bem como outras de $A$ gazeta, três delas por nós extraídas da coleção incompleta do jornal paulistano existente na Biblioteca Nacional. Ainda outras foram recolhidas de um maço de recortes, infelizmente na sua maioria sem data, encontrados entre os papéis do A., maço que trazia a indicação (não com letra do poeta): Crônicas de Guy d'Alvim. ${ }^{28}$

Assim, entre seleções e exclusões, as crônicas e versos humorísticos de Alphonsus permanecem território pouquíssimo explorado, sendo Mendigos a região limítrofe a que alguns críticos - de passagem - chegaram a se aventurar. O livro inegavelmente desigual em que Henriqueta Lisboa ${ }^{29}$ chegou a ver, em alguns enredos, uma reminiscência de Hoffmann, abriga limitações evidentes, mas pode - na contramão e em conjunto com as demais produções para jornais do autor - fornecer munição de bom calibre à critica que deseje ultrapassar os problemas mais comumente suscitados até o momento pela obra do escritor mineiro.

\section{4) Acidentes e percursos}

Uma questão em especial propõe-se ao leitor de Mendigos. Embora organizado pelo próprio autor, o livro parece carecer de um princípio de coesão interno seja temático, seja estilístico, seja de outra natureza. Narrativas sobre leprosos, pesadelos envolvendo cemitérios com toques macabros, um clube de suicidas, mulheres misteriosamente sedutoras com seus "olhos vítreos", amadas mortas ou adúlteras são intercaladas com outras embutindo reflexões sobre o efeito de Wagner nas vacas leiteiras, ou juízos críticos sobre a obra de Tolstoi, o Carnaval, os órgãos internos do corpo humano e sua cura, o comportamento indecoroso dos políticos, a defesa das Academias de Letras, aspectos de história antiga, misérias de um professor primário, ou ainda comentários sobre a dança e o rei Davi.

\footnotetext{
${ }^{28}$ GUIMARAENS, 1960, p. 735.

${ }^{29}$ LISBOA, 1945.
} 
Evidentemente, o princípio coesivo é externo à coletânea e os textos se unificam a ponto de poderem ser convertidos em uma "obra" tão somente pela procedência comum (a crônica datada de jornal, submetida a uma seleção pessoal).

A pesquisadosa Arline Anglade-Aurand, ${ }^{30}$ analisando de passagem a obra Mendigos e também as Crônicas de Guy d'Alvim, procura equacionar o problema. Para publicação, entende que Alphonsus teria escolhido os artigos mais próximos de seu fervor religioso e de sua curiosidade metafísica, com interesse pela magia, pelo ceticismo e pelo hinduísmo que influenciaram a maior parte de seus contos e crônicas. Para ela, seria possível resgatar da leitura de Mendigos uma tripla corrente de influências representada primeiro por Villiers de L 'Isle Adam, em seguida pelos "magos" e os filósofos de salão que escreveram ensaios sobre os assuntos em voga na época, enfim pelos prosadores do século XIX (Chateaubriand, Balzac, Flaubert, Maupassant, Zola). De outra parte, ainda em Mendigos, mas sobretudo em diversos artigos publicados nos jornais e nas Crônicas de Guy d'Alvim, apareceria um outro aspecto de Alphonsus: a crítica, influenciada por Taine, Renan, Brunetière e Roquette.

Como seu estudo não esmiuça o problema, talvez houvesse aí um percurso a ser trilhado em busca de um aprofundamento da reflexão. Além disso, igualmente instigante poderia vir a ser o mapeamento da ocorrência de diversos procedimentos temáticos ou formais do autor, no sentido de tentar compreender eventuais pressupostos relativos a sua concepção de atividade intelectual que, com freqüência, deixam-se entrever na dispersão. Além das versões diferentes para jornais diferentes e para publicação em livro, importaria observar em que medida mudanças de tom e de procedimentos poderiam ou nã $\mathrm{O}^{31}$ corresponder a diferentes momentos da compreensão do autor em relação ao mundo que o cercava e ao veículo através do qual ele tentava se acercar deste mundo.

Se observado, por exemplo, o tratamento dispensado em várias crônicas à participação das mulheres na sociedade, não deixa de ser curioso e historicamente pertinente observar o modo como se sustentam

\footnotetext{
${ }^{30}$ ANGLADE-AURAND, 1970.

${ }^{31}$ Parece certo que boa parte (quanto?) das divergências entre os textos pode ser associada, simplesmente, à natureza da crônica enquanto gênero atrelado ao caráter momentâneo de seu meio de divulgação.
} 
conceitos que, aos olhos de hoje, soam (e são) profundamente conservadores ou antiquados. Contudo, se mirados o mais próximo possível da perspectiva em que foram produzidos, podem ilustrar de modo decisivo a compreensão de e/ou a crítica às representações de sociedade que implicam.

Deste modo, pleitear jocosamente a necessidade de dotes culinários para as donzelas e ironizar com acidez a participação eleitoral feminina ou com bom humor seu ingresso às repartições públicas são atitudes discursivas que convivem com a discussão e a censura à diferença socialmente aprovada entre homens e mulheres perante o adultério. Ou ainda, a aprovação do divórcio em realidades sociais que o viabilizassem faz-se acompanhar de sua desaprovação para os moldes da família e da mentalidade brasileira (mineira?) de então.

Se o cronista - ao comentar e argumentar a favor deste ou daquele tema - acaba sendo, por definição, um formador de opiniões, faz gosto observar o modo como este cronista em específico cerca cuidadosamente suas intervenções de trechos, digressões ou crônicas inteiras em que se ocupa em aparelhar e fortalecer o processo reflexivo do leitor a propósito da realidade, da linguagem (literária ou não) e da interseção entre ambas. Além dos questionamentos a propósito de diversos aspectos da vida social, questões metalingüísticas são freqüentes. Ocorre tanto a discussão sobre o sentido de palavras e da origem de termos com clara intenção educativa, quanto a reflexão (disfarçada no escracho) sobre o caráter cambiante das línguas e a necessidade de bom senso em sua utilização .

Assim, em "Arengas e palavrórios" 32 a censura aos discursos vazios faz-se acompanhar de ironias ao jargão das "colunas sociais" da época, à subserviência lingüisticamente veiculada do mestre-escola mal remunerado, aos "laudares patrióticos" do "romântico e gaforinhento poeta local". "Cavaco lingüístico"33 ironiza a figura mal-humorada de um mestre escandalizado com os estrangeirismos disseminados pela língua, enquanto em "Na terça-feira gorda", ${ }^{34}$ o encontro entre o "Antigo vernáculo" e "O popularíssimo" resulta na derrota inevitável do primeiro.

O estatuto do texto literário enquanto fonte de cultura, prazer e amolação também é posto em discussão. A crônica "Remédios para

\footnotetext{
${ }^{32}$ GUIMARAENS, 1960, p. 439-441.

33 GUIMARAENS, 1960, p. 456-458.

${ }^{34}$ GUIMARAENS, 1960, p. 474.
} 
Insônias", ${ }^{35}$ por exemplo, advoga os valores terapêuticos da Bíblia, de um poema heróico em dez cantos, dos Suspiros Poéticos de Magalhães, dos artigos do Sr. Martins de Carvalho ... apenas duas páginas antes, outro texto analisa a força do Quixote de Cervantes (retomado, aliás, em várias crônicas). Já "A arte de fazer bons versos", põe em discussão livro de Osório Duque Estrada sobre versificação:

Vê-se, porém que o livro em questão será apenas um compêndio prático, onde os infinitos romeus que pululam por esses brasis afora possam decantar as suas julietas sem lhes quebrar os pés... dos versos encomiásticos; o namorado que ao primeiro olhar da bem-amada sentiu brotar dentro de si a fonte castália da inspiração apolínea, terá naquele perfeito manual prático as regras necessárias ao seu caso patológico e psíquico, podendo encaixar com toda a segurança nas dez bem escondidas sílabas de uma linha toda a sua falta de idéia e inteligência. /Debaixo desse ponto de vista, o livro terá um sucesso enorme, e para que as suas edições se multipliquem vertiginosamente, bastará apenas que cada um daqueles que conversam com as camenas na fértil terra brasileira o adquira, depositando-o cuidadosamente entre as cartas das suas dulcinéias. ${ }^{36}$

Assumindo sem falso pudor o tom próprio a sua tribuna, ${ }^{37}$ o cronista entabula seu diálogo com seu público. Há, em verdade, uma solução de continuidade entre este processo, a utilização de pessoas da comunidade para seus pseudônimos d'O alfinete (recurso de empatia com o leitor?), a opção por repertórios acessíveis de referências (como a Bíblia e suas parábolas) para a discussão, por exemplo, das oligarquias e, finalmente, a insistência com que o poeta se empenha por toda a vida em publicar seus versos nos jornais (com tiragens bem mais generosas que aquelas alcançadas para seus livros por sua frágil bolsa).

35 GUIMARAENS, 1960, p. 654-655.

${ }^{36}$ GUIMARAENS, 1960, p. 658.

${ }^{37}$ Os jornais entram em cena com "Um sapateiro de fama universal". Lá, a referência à estátua romana de Pasquino (usada pelo povo para suporte de bilhetes que davam curso livre à maledicência) é tomada como a origem "das mofinas e das seções livres de alguns jornais da atualidade, bem como dos editoriais de outros". (GUIMARAENS, 1960, p. 474) 
Paralelamente, a freqüência com que se discutem problemas de dinheiro, questões de sobrevivência, crises gerais e misérias (econômicas) particulares dão ao homem (oculto sob a face do jornalista e do editor) uma concretude material que se formaliza (pessoal e institucionalmente) na versificação de reclames publicitários, para citar um caso. Se o jornal se viabiliza enquanto órgão oficial ao se inserir no quadro econômico da sociedade da qual é porta-voz, o jurista desempregado lança mão - com bom humor - de sua habilidade como versejador na manutenção de seu ganha-pão editorial.

A venda do Gil Herédia, ou do Juca de Aguiar, as fazendas de A. Lages \& Mascarenhas, os produtos do Oliveira \& Lima, as chitas do Olímpio de Oliveira, ou a loira bock-ale da casa Costa \& Cirino, todos de 1904, com seu ar de desprestígio e somenos nivelam-se às causas processuais que, na década seguinte, vão ocupar o tempo civilmente rentável do juiz de direito estabelecido na comarca de Mariana. Na outra face da moeda, Alphonsus de Guimaraens, o poeta.

Entre o jornalista que se inquietava com a bolsa e o simbolista obcecado por Caronte, a precariedade geral, o terreno acidentado que liga uma e outra cenas. Da busca consciente dos jornais e similares, passando pelo financiamento político e pelas mal sucedidas tentativas de autofinanciamento até o silêncio editorial de dois ou três projetos ${ }^{38}$ e a precariedade das finanças pessoais de quem se divide entre duas atividades e considera "principal" a que não rende dinheiro algum... o percurso de Alphonsus guarda uma inegável homologia com os processos por que passavam a literatura e outros literatos no Brasil, no encontro entre os séculos XIX e XX. ${ }^{39}$

Investigar esta homologia que devolve o poeta excêntrico ao contexto concreto em que existiu talvez contribuísse com a fragilização da perspectiva mitificada normalmente adotada em seus estudos. Fragilizado o mito, é possível que a força e as limitações do poeta e do prosador - nas múltiplas facetas que imprimiu à atividade escrita adquirissem contornos mais nítidos, menos ideais.

\footnotetext{
${ }^{38}$ As crônicas de João Carrilho, as de Guy d' Alvim e a Pastoral aos crentes do amor e da morte que o filho João Alphonsus "encurta" para obter uma publicação pela editora de Monteiro Lobato, em 1923, dois anos após a morte do poeta. ${ }^{39}$ Ver: LAJOLO e ZILBERMAN, 1991 e LAJOLO e ZILBERMAN, 1996.
} 


\section{Referências Bibliográficas}

ANGLADE-AURAND, Arline. Les influences françaises sur Alphonsus de Guimaraens. Toulouse. [1970]. Thése presentée devant l'Université de Toulouse pour 1e Doctorat $3^{\circ}$ cycle.

BROCA, Brito. Alphonsus de Guimaraens, jornalista. Suas crônicas no "Mercantil", um aspecto inédito do poeta de Kiriale. A manhã , Rio de Janeiro, 20 de maio de 1951. Letras e artes, ano 6, n. 207, p.4.

CAMPOS, Cézar Câmara de Lima. Gente de um tempo. Toda uma época. Gonzaga Duque, Mário Pederneiras, os simbolistas. A noite, Rio de Janeiro, 29 jul. 1921. In: MURICY, Andrade. Panorama do movimento simbolista brasileiro. Rio de Janeiro: Imprensa Nacional, 1951-1952. v.1. p. 560-562.

CASASSANTA, Mário. O jornal de Alphonsus. Folha de Minas, Belo Horizonte, 16 jul. 1946. sec. 1, p. 3.

COElHO, Vulmar. Alphonsus, Humorista e Satírico. Revista da Academia Mineira de Letras, Belo Horizonte, v. 14, 1934, p. .

CRISPIM, Antônio. (Carlos Drummond de Andrade). João Ventania: um dos lados de Alphonsus de Guimaraens. Leitura, Rio de Janeiro: ano 16, no 7, p. 25-33, jan. 1958.

GUIMARAENS FILHO, Alphonsus de. Alphonsus de Guimaraens no seu ambiente. Rio de Janeiro: Fundação Biblioteca Nacional, Dep. Nacional do Livro, 1995.

GUIMARAENS, Alphonsus de. Cai a garoa (Recordações de São Paulo). In:

Obra completa. São Paulo: Aguilar, 1960. p.459-462.

GUIMARAENS, João Alphonsus de. Notícia biográfica. In: GUIMARAENS, Alphonsus de. Obra completa. São Paulo: Aguilar, 1960. p.

HOLANDA, Aurélio Buarque de. Pobre Alphonsus! Pobre Alphonsus! Jornal de letras, Rio de Janeiro, ano 1, n. 4, p. 6, out. 1949.

LAJOLO, Marisa e ZILBERMAN, Regina. A formação da leitura no Brasil. São Paulo: Ática, 1996.

LAJOLO, Marisa e ZILBERMAN, Regina. A leitura rarefeita: livro e literatura no Brasil. São Paulo: Brasiliense, 1991.

LISBOA, Henriqueta. Vida e obra de Alphonsus de Guimaraens. Rio de Janeiro: Agir, 1945. 


\section{Resumo}

Este texto objetiva discutir as relações entre a produção literária de Alphonsus de Guimaraens e suas incursões pelo jornalismo. Analisamse, para tanto, elementos contextuais e textuais que apontam para uma concepção de literatura e de inserção social do literato de que não se descartam as considerações materiais concretas. A atuação jornalística, de que a carreira deste poeta sempre se fez acompanhar, parece, neste caso como em outros, fornecer elementos que permitem repensar abordagens muito idealizantes mesmo para escritores como os simbolistas e decadentes do final do século XIX que, à primeira vista, parecem demandar a referida idealização. Assim, a inserção material concreta da atividade literária se apresenta ladeada pela atividade jornalística, em uma parceria que talvez seja mais esclarecedora do que se tem usualmente considerado. Apontam-se, aqui, algumas perspectivas no sentido de se expandirem as lacunares referências bibliográficas que fazem referência à mencionada parceria.

\section{Résumé}

Ce travail a comme objetif discuter les rélations entre les activités de l'écrivain Alphonsus de Guimaraens comme poéte et comme journaliste. Pour réaliser cette discussion, on analyse des éléments contextuelles et textuelles presentes dans ces écrits et qui permettent d'entrevoir une conception de littérature et de participation social du littérateur que n’ignore pas les considérations concrètes impliquées. L'activité journalistique constante de Guimaraens paraître fournir des éléments pour permettre d'abandoner des approches trop idéalistes. On voit ici un partenariat entre les écrits pour le journal e les écrits littéraires. Ce partenariat pourra, peut-être, permettre de comprendre quelques aspects pas bien discutés de Guimaraens. On indique, dans ce travail, quelques perspectives pour l'expansion de la documentation lacunaire a propos de le partenariat évoqué. 